\title{
Direct-Acting Antivirals for Hepatitis C: Predictors of Early Discontinuation in the Real World
}

\author{
Marina Amaral de Ávila Machado, PhD; Cristiano Soares de Moura, PhD; \\ Marina Klein, MD, MSc, FRCPC; Kevin Winthrop, MD, MPH; Bruce Carleton, BSc, PharmD; \\ Michal Abrahamowicz, PhD; Jordan Feld, MD, MPH; Jeffrey R. Curtis, MD, MS, MPH; \\ Marie-Eve Beauchamp, PhD; and Sasha Bernatsky, MD, PhD
}

\begin{abstract}
BACKGROUND: The treatment for hepatitis $\mathrm{C}$ virus (HCV) infection has evolved over time, and direct-acting antivirals (DAA) have revolutionized HCV therapy.

OBJECTIVES: To (a) assess early treatment discontinuation and (b) identify predictors of early discontinuation in a cohort of patients receiving secondgeneration DAAs.

METHODS: We identified HCV patients newly prescribed simeprevir/sofosbuvir (SIM/SOF), ledipasvir/sofosbuvir (LDV/SOF), ombitasvir/paritaprevir/ ritonavir + dasabuvir (OPrD), sofosbuvir/velpatasvir (SOF/VEL), elbasvir/ grazoprevir (EBR/GZR), and glecaprevir/pibrentasvir (GLE/PIB) between 2014 and 2017. Early discontinuation was defined as duration of therapy less than 8 weeks. Multivariable logistic regression was performed to evaluate the association of drug regimens and potential predictive factors to early discontinuation.
\end{abstract}

RESULTS: We identified 26,098 DAA-treated patients: $67.8 \%$ with LDV/SOF, $9.9 \%$ with $\mathrm{OPrD}, 8.5 \%$ with SIM/SOF, $7.8 \%$ with SOF/VEL, $5.2 \%$ with EBR/ GZR, and $0.8 \%$ with GLE/PIB. With approval of new therapies in 2016 and 2017, use of OPrD, LDV/SOF, and SIM/SOF declined substantially. At baseline, there was some heterogeneity of past HCV drug use and comorbidity across groups; patients on SIM/SOF had the highest frequency of previous interferon, cirrhosis, and decompensated cirrhosis. Most HCV patients received therapy for 8-12 weeks; fewer patients went through 16-week and 24 -week therapy courses. Early discontinuation rates $(95 \% \mathrm{CI})$ were $7.1 \%(6.0-8.2)$ for SIM/SOF, 3.2\% (2.9-3.5) for LDV/SOF, 9.6\% (8.5-10.7) for OPrD, 3.1\% (2.3-3.8) for SOF/VEL, 4.2\% (3.1-5.3) for EBR/GZR, and $2.5 \%(0.3-4.7)$ for GLE/PIB. In multivariable analyses, versus OPrD, patients starting other drug regimens were less likely to discontinue therapy early. Early discontinuation was more common in women, patients with baseline anemia, and Medicare and Medicaid patients.

CONCLUSIONS: These real-world data confirm low rates of early discontinuation in users of second-generation DAAs. Future research focusing on socioeconomic and sex/gender issues may help further optimize care for patients with HCV.

J Manag Care Spec Pharm. 2019;25(6):697-704

Copyright $\odot 2019$, Academy of Managed Care Pharmacy. All rights reserved.

\section{What is already known about this subject}

Second-generation direct-acting antivirals are effective in hepatitis $C$ virus treatment.

Real-world data are lacking on therapy discontinuation and completion of these regimens in clinical practice.

\section{What this study adds}

Among patients using simeprevir/sofosbuvir, ledipasvir/sofosbuvir, ombitasvir/paritaprevir/ritonavir + dasabuvir, sofosbuvir/ velpatasvir, elbasvir/grazoprevir, and glecaprevir/pibrentasvir, less than $10 \%$ discontinue therapy before 8 weeks.

Early discontinuation of therapy (before 8 weeks) was more common in women, patients with baseline anemia, and patients covered by Medicare and Medicaid.

$\mathrm{H}$ epatitis $\mathrm{C}$ virus (HCV) infection is a global health problem. In 2015, the worldwide incidence was 24 cases per 100,000 persons. ${ }^{1}$ Approximately $75 \%-85 \%$ of persons infected by HCV will develop chronic infection. As of 2015, 71 million individuals around the world, or $1 \%$ of the global population, were living with this chronic disease., ${ }^{1,2}$ Over time chronic HCV infection can cause serious complications, such as cirrhosis and hepatocellular carcinoma, which are major causes of mortality from HCV infection. There is currently no vaccine for $\mathrm{HCV}$, and unsafe health care procedures and injection of drugs are the leading causes of new infections. ${ }^{1,2}$

The treatment for HCV infection has evolved over time, and clinical guidelines are being updated constantly. Since 2013, the current standard treatment has consisted of 2 or more second-generation direct-acting antivirals (DAAs) with or without ribavirin. ${ }^{3}$ DAAs are oral medications that directly inhibit the replication cycle of $\mathrm{HCV}$ and have led to higher response rate and tolerability of treatment. Second-generation DAAs can cure $90 \%$ or more of patients who complete therapy, measured by sustained virologic response (SVR) 12 weeks after treatment completion in clinical trials and observational studies. ${ }^{4-7}$

Previous studies with non-DAA regimens (interferon and ribavirin) have highlighted high rates of therapy discontinuation, often due to adverse events, and associated low adherence to reduced effectiveness in clinical practice..$^{8-10}$ Therapy discontinuation for adverse events continue to be common with first-generation DAA regimens, telaprevir and boceprevir, used as a triple therapy along with interferon and ribavirin. ${ }^{11,12}$ Second-generation DAAs have had substantially better results, with $80 \%-90 \%$ of patients completing therapy with simeprevir/sofosbuvir (SIM/SOF), ledipasvir/sofosbuvir (LDV/SOF), 
and ombitasvir/paritaprevir/ritonavir + dasabuvir (OPrD) ${ }^{13-15} \mathrm{~A}$ case series study with patients using LDV/SOF suggested that the achievement of SVR is associated with strong adherence. ${ }^{16}$ Rates of treatment completion in real-world settings are still unknown for sofosbuvir/velpatasvir (SOF/VEL), elbasvir/grazoprevir (EBR/GZR), and glecaprevir/pibrentasvir (GLE/PIB).

Adherence to and completion of treatment is important to achieving SVR, and the choice of the most beneficial DAA regimen for a specific patient will be based on patients' characteristics and previous therapy experience. ${ }^{3,17}$ Moreover, there is a concern whether history of illicit drug or alcohol use is a risk factor for nonadherence, and the literature shows that this is a barrier to treating patients. ${ }^{18}$ For this reason, it is crucial to evaluate therapy discontinuation and the factors that predict discontinuation in real-world settings to optimize treatment and patient outcomes. Therefore, in this study, we compared early therapy discontinuation in $\mathrm{HCV}$ patients receiving second-generation DAAs between 2014 and 2017 and predictor factors of early discontinuation.

\section{Methods}

\section{Data Source}

In this retrospective cohort study, we used data from the MarketScan Commercial, Medicare, and Medicaid databases for the period between January 1, 2011, and December 31, 2017. These databases comprise data from employers, health plans, and state Medicaid agencies and include records of inpatient services, inpatient admissions, outpatient services, and prescription drug claims. ${ }^{19}$ Medicare provides a health insurance program for people aged 65 years or older and for adults with permanent disabilities, and Medicaid provides health insurance for people with low incomes..$^{20,21}$

\section{Inclusion/Exclusion Criteria}

We studied adults with HCV (at least aged 18 years) who were newly prescribed a second-generation DAA between January 1, 2014, and December 30, 2017. We considered 6 drug regimens: combination of SIM/SOF and fixed-dose tablets of LDV/ SOF, OPrD, SOF/VEL, EBR/GZR, and GLE/PIB. Patients were allowed to use ribavirin concomitantly. The date of the first pharmacy claim for the combination regimen represented the cohort entry date. We limited the analyses to individuals with no use of these medications any time before cohort entry (minimum 12 months, but using all available data), although the previous use of interferon, ribavirin, boceprevir, and telaprevir was allowed. HCV patients were identified as individuals with at least 1 diagnostic code for HCV in either an inpatient or an outpatient claim at least 1 year before cohort entry (Appendix A, available in online article). Additionally, individuals had to have at least 12 continuous months of medical and pharmacy coverage before cohort entry, and we required individuals to have at least 8 weeks of follow-up. The follow-up period was defined from the cohort entry until the earliest date of inhospital death, loss of medical and pharmacy coverage, or end of study (December 31, 2017).

\section{Outcome}

Duration of therapy was estimated as the total duration of the DAA prescriptions filled (sum of days supplied). A therapy course was considered terminated if no prescription was issued within 45 days after the latest prescription was exhausted. ${ }^{22}$ Early discontinuation was defined as duration of therapy less than 8 weeks. We categorized patients receiving therapy for 8 , 12,16 , and 24 weeks.

\section{Covariates}

Demographic and other baseline variables were determined at cohort entry and included age; sex; region of residence (urban vs. rural); full-time employment; type of health plan coverage (commercial plans, Medicare, and Medicaid); and race (only available in Medicaid data). Potential confounders were measured during 1 year before cohort entry: (a) past use of HCV treatment (interferon, ribavirin, boceprevir, and telaprevir); (b) 3 indicators of health service use including emergency department visits, physician visits, and hospitalizations; and (c) comorbidities (Charlson Comorbidity Index, cirrhosis, decompensated cirrhosis, anemia, diabetes, human immunodeficiency virus [HIV] infection, drug abuse, and alcohol abuse). ${ }^{23-25}$ All comorbidities were identified by at least 1 diagnostic code in outpatient physician visit or hospitalization. In addition, HIV infection was confirmed by at least 1 prescription for antiretroviral therapy. A complete list of diagnostic codes is presented in Appendix A. Additionally, we defined use of ribavirin (ever-users vs. never-users) during 8 weeks of follow-up (required minimum follow-up for all patients).

\section{Statistical Analyses}

We estimated the proportion of early discontinuation and 95\% confidence interval (CI) for each drug regimen in the overall cohort and stratified by sex and cirrhotic/noncirrhotic patients. We estimated the proportions and $95 \%$ CIs of patients who received $8,12,16$, and 24 weeks of therapy for each drug regimen in the overall cohort and stratified by cirrhotic/ noncirrhotic patients. Multivariable logistic regression was performed to estimate the odds ratios (OR), with 95\% CIs, for the associations between each drug regimen and the binary outcome of early discontinuation adjusted for some covariates previously described, such as age, sex, year of cohort entry, health plan coverage, Charlson Comorbidity Index score, cirrhosis, anemia, diabetes, HIV infection, drug abuse, alcohol abuse, 3 indicators of health service use, and use of ribavirin during follow-up. The reference group for drug regimens was 
Direct-Acting Antivirals for Hepatitis C: Predictors of Early Discontinuation in the Real World

TABLE 1 Baseline Characteristics According to Initial Drug Regimen ( $N=26,098)$

\begin{tabular}{|c|c|c|c|c|c|c|c|c|c|c|c|c|c|c|}
\hline \multirow{2}{*}{$\begin{array}{l}\text { Variables } \\
\text { Male, n (\%) }\end{array}$} & \multicolumn{2}{|c|}{$\begin{array}{l}\text { All Patients } \\
\mathrm{N}=26,098\end{array}$} & \multicolumn{2}{|c|}{$\begin{array}{c}\text { SIM/SOF } \\
\mathrm{n}=2,224 \\
(8.5 \%)\end{array}$} & \multicolumn{2}{|c|}{$\begin{array}{c}\text { LDV/SOF } \\
\mathrm{n}=17,688 \\
(67.8 \%)\end{array}$} & \multicolumn{2}{|c|}{$\begin{array}{c}\text { OPrD } \\
\mathrm{n}=2,590 \\
(9.9 \%)\end{array}$} & \multicolumn{2}{|c|}{$\begin{array}{c}\text { SOF/VEL } \\
\mathrm{n}=2,036 \\
(7.8 \%)\end{array}$} & \multicolumn{2}{|c|}{$\begin{array}{c}\text { EBR/GZR } \\
\mathrm{n}=1,361 \\
(5.2 \%)\end{array}$} & \multicolumn{2}{|c|}{$\begin{array}{c}\text { GLE/PIB } \\
\mathrm{n}=199 \\
(0.8 \%)\end{array}$} \\
\hline & 15,795 & $(60.5)$ & 1,389 & $(62.5)$ & 10,751 & $(60.8)$ & 1,569 & $(60.6)$ & 1,174 & $(57.7)$ & 817 & $(60.0)$ & 95 & $(47.7)$ \\
\hline Age, years, median (IQR) & 58 & $(53-62)$ & 58 & $(54-62)$ & 58 & $(53-62)$ & 58 & $(53-61)$ & 56 & $(47-60)$ & 58 & $(53-62)$ & & $(45-60)$ \\
\hline \multicolumn{15}{|l|}{ Year of cohort entry, $\mathrm{n}(\%)$} \\
\hline 2014 & 4,032 & $(15.5)$ & 2,171 & $(97.6)$ & 1,859 & $(10.5)$ & 2 & $(0.1)$ & 0 & $(0)$ & 0 & $(0)$ & 0 & $(0)$ \\
\hline 2015 & 9,204 & (35.3) & 52 & $(2.3)$ & 7,643 & $(43.2)$ & 1,509 & $(58.3)$ & 0 & $(0)$ & 0 & $(0)$ & 0 & $(0)$ \\
\hline 2016 & 6,954 & $(26.7)$ & 0 & $(0)$ & 4,902 & $(27.7)$ & 947 & $(36.6)$ & 687 & $(33.7)$ & 418 & $(30.7)$ & 0 & $(0)$ \\
\hline 2017 & 5,908 & $(22.6)$ & 1 & $(<0.1)$ & 3,284 & $(18.6)$ & 132 & $(5.1)$ & 1,349 & $(66.3)$ & 943 & $(69.3)$ & 199 & $(100)$ \\
\hline Urban, n (\%)a & 16,460 & (90.6) & 1,630 & $(91.5)$ & 11,719 & $(90.5)$ & 1,735 & $(90.7)$ & 1,025 & $(89.4)$ & 298 & $(94.0)$ & 53 & $(96.4)$ \\
\hline Full-time employment, n (\%)a & 9,996 & $(55.0)$ & 890 & $(49.9)$ & 7,140 & $(55.1)$ & 1,107 & $(57.9)$ & 711 & $(62.0)$ & 118 & $(37.2)$ & 30 & $(54.6)$ \\
\hline \multicolumn{15}{|l|}{ Race, $\mathrm{n}(\%)^{\mathrm{b}}$} \\
\hline $\begin{array}{l}\text { White } \\
\end{array}$ & 3,724 & $(49.6)$ & 210 & $(47.5)$ & 1,847 & $(40.9)$ & 364 & $(54.0)$ & 675 & $(84.5)$ & 519 & $(54.8)$ & 109 & $(80.2)$ \\
\hline Black & 2,580 & $(34.3)$ & 160 & $(36.2)$ & 1,711 & $(37.9)$ & 250 & $(37.1)$ & 68 & $(8.5)$ & 368 & $(38.8)$ & 23 & $(16.9)$ \\
\hline Hispanic & 119 & (1.6) & 11 & $(2.5)$ & 63 & (1.4) & 9 & (1.3) & 16 & $(2.0)$ & 18 & (1.9) & 2 & (1.5) \\
\hline Other & 1,090 & $(14.5)$ & 61 & $(13.8)$ & 893 & $(19.8)$ & 51 & $(7.6)$ & 40 & $(5.0)$ & 43 & $(4.5)$ & 2 & $(1.5)$ \\
\hline \multicolumn{15}{|l|}{ Health plan coverage, $\mathrm{n}(\%)$} \\
\hline Commercial plans & 15,599 & $(59.8)$ & 1,468 & $(66.0)$ & 11,095 & $(62.7)$ & 1,773 & $(68.5)$ & 1,026 & $(50.4)$ & 192 & $(14.1)$ & 45 & $(22.6)$ \\
\hline Medicare & 2,568 & (9.8) & 314 & $(14.1)$ & 1,859 & $(10.5)$ & 140 & $(5.4)$ & 120 & $(5.9)$ & 125 & $(9.2)$ & 10 & $(5.0)$ \\
\hline Medicaid & 7,931 & $(30.4)$ & 442 & $(19.9)$ & 4,734 & $(26.8)$ & 677 & $(26.1)$ & 890 & $(43.7)$ & 1,044 & $(76.7)$ & 144 & $(72.4)$ \\
\hline $\begin{array}{l}\text { Charlson Comorbidity Index, } \\
\text { mean (SD) }\end{array}$ & 2.0 & $(2.3)$ & 2.3 & $(2.5)$ & 2.0 & $(2.3)$ & 1.4 & $(1.9)$ & 2.0 & $(2.0)$ & 2.7 & $(2.6)$ & 1.5 & $(2.3)$ \\
\hline \multicolumn{15}{|l|}{ Comorbidities, n (\%) } \\
\hline Cirrhosis & 5,510 & $(21.1)$ & 888 & $(39.9)$ & 3,588 & $(20.3)$ & 352 & $(13.6)$ & 382 & $(18.8)$ & 288 & $(21.2)$ & 12 & $(6.0)$ \\
\hline Anemia & 2,382 & $(9.1)$ & 272 & $(12.2)$ & 1,579 & $(8.9)$ & 164 & $(6.3)$ & 169 & $(8.3)$ & 183 & $(13.5)$ & 15 & $(7.5)$ \\
\hline Decompensated cirrhosis & 2,460 & $(9.4)$ & 416 & $(18.7)$ & 1,576 & $(8.9)$ & 120 & $(4.6)$ & 212 & $(10.4)$ & 122 & $(9.0)$ & 14 & $(7.0)$ \\
\hline Diabetes & 5,309 & (20.3) & 523 & $(23.5)$ & 3,650 & $(20.6)$ & 452 & (17.5) & 305 & (15.0) & 352 & (25.9) & 27 & (13.6) \\
\hline HIV infection & 806 & (3.1) & 50 & (2.3) & 628 & (3.6) & 61 & (2.4) & 29 & (1.4) & 36 & $(2.7)$ & 2 & (1.0) \\
\hline Drug abuse & 2,094 & $(8.0)$ & 101 & $(4.5)$ & 1,320 & $(7.5)$ & 144 & $(5.6)$ & 329 & $(16.2)$ & 174 & (12.8) & 26 & (13.1) \\
\hline Alcohol abuse & 2,063 & $(7.9)$ & 95 & $(4.3)$ & 1,406 & $(8.0)$ & 140 & (5.4) & 277 & (13.6) & 134 & (9.9) & 11 & (5.5) \\
\hline $\begin{array}{l}\text { Past use of interferon, ribavirin, } \\
\text { telaprevir, or boceprevir, } \mathrm{n}(\%)^{\mathrm{c}}\end{array}$ & 407 & (1.6) & 105 & $(4.7)$ & 118 & $(0.7)$ & 159 & $(6.1)$ & 16 & $(0.8)$ & 9 & $(0.7)$ & 0 & (0) \\
\hline Interferon & 92 & $(0.4)$ & 57 & $(2.6)$ & 33 & $(0.2)$ & 1 & $(0)$ & 0 & $(0)$ & 1 & $(0.1)$ & 0 & $(0)$ \\
\hline Ribavirin & 399 & $(1.5)$ & 100 & $(4.5)$ & 115 & $(0.7)$ & 159 & $(6.1)$ & 16 & $(0.8)$ & 9 & $(0.7)$ & 0 & $(0)$ \\
\hline Telaprevir & 30 & $(0.1)$ & 28 & $(1.3)$ & 2 & $(0)$ & 0 & $(0)$ & 0 & $(0)$ & 0 & $(0)$ & 0 & $(0)$ \\
\hline Boceprevir & 19 & $(0.1)$ & 12 & $(0.5)$ & 7 & $(0)$ & 0 & $(0)$ & 0 & $(0)$ & 0 & $(0)$ & 0 & $(0)$ \\
\hline $\begin{array}{l}\text { Ribavirin use during follow-up, } \\
\mathrm{n}(\%)^{\mathrm{d}}\end{array}$ & 3,202 & $(12.3)$ & 361 & $(16.2)$ & 716 & $(4.1)$ & 1,902 & $(73.4)$ & 150 & $(7.4)$ & 73 & $(5.4)$ & 0 & (0) \\
\hline $\begin{array}{l}\text { Number of physician visits, } \\
\text { mean (SD) }\end{array}$ & 13.0 & $(13.4)$ & 15.5 & $(14.4)$ & 12.7 & (11.9) & 10.9 & $(10.4)$ & 12.9 & $(16.3)$ & 16.9 & $(23.3)$ & 11 & $(26.3)$ \\
\hline Number of ED visits, mean (SD) & 1.0 & $(2.3)$ & 0.8 & $(1.7)$ & 0.9 & $(2.4)$ & 0.9 & $(1.9)$ & 1.2 & $(2.4)$ & 1.6 & $(2.6)$ & 1.9 & (3.3) \\
\hline $\begin{array}{l}\text { Number of hospitalizations, } \\
\text { mean (SD) }\end{array}$ & 0.3 & $(0.9)$ & 0.4 & $(1.0)$ & 0.3 & $(0.8)$ & 0.2 & $(0.6)$ & 0.4 & $(1.0)$ & 0.4 & $(1.0)$ & 0.6 & $(1.2)$ \\
\hline
\end{tabular}

${ }^{a}$ Missing values for Medicaid-covered patients $(n=7,931)$.

${ }^{b}$ Missing values for commercial-plan and Medicare-covered patients $(n=18,585)$

cUse in the year before cohort entry.

dUse during 8 weeks of follow-up (required minimum follow-up for all patients).

$E B R / G Z R=$ elbasvir/grazoprevir; $E D=$ emergency department; $G L E / P I B=$ glecaprevir/pibrentasvir; $I Q R=$ interquartile range; $L D V / S O F=$ ledipasvir/sofosbuvir;

$\mathrm{OPrD}=$ ombitasvir/paritaprevir/ritonavir + dasabuvir; $S D=$ standard deviation; SIM/SOF = simeprevir/sofosbuvir; SOF/VEL = sofosbuvir/velpatasvir.

OPrD. In addition, a 5-degree-of-freedom likelihood ratio test, at alpha $=0.05$, was used to test if the adjusted early discontinuation rates differed between users of different drug regimens. This test does not depend on the choice of reference group.
We repeated the regression model in a subgroup of Medicaid patients adding a variable for race (black vs. nonblack, which included white, Hispanic, and others). All analyses were conducted using SAS version 9.4 (SAS Institute, Cary, NC). 
Direct-Acting Antivirals for Hepatitis C: Predictors of Early Discontinuation in the Real World

TABLE 2 Proportion (95\% Cl) of Patients with Early Discontinuation of Therapy (<8 Weeks)

\begin{tabular}{|c|c|c|c|c|c|c|c|c|c|c|c|}
\hline \multirow{2}{*}{$\begin{array}{l}\text { Early Discontinuation } \\
\text { Overall cohort }\end{array}$} & \multicolumn{2}{|c|}{$\begin{array}{l}\text { SIM/SOF } \\
\%(95 \% \text { CI })\end{array}$} & \multicolumn{2}{|c|}{$\begin{array}{l}\text { LDV/SOF } \\
\%(95 \% \mathrm{CI})\end{array}$} & $\begin{array}{c}\text { OPrD } \\
\%(95 \% \mathrm{CI}) \\
\end{array}$ & \multicolumn{2}{|c|}{$\begin{array}{l}\text { SOF/VEL } \\
\%(95 \% \mathrm{CI})\end{array}$} & \multicolumn{2}{|c|}{$\begin{array}{l}\text { EBR/GZR } \\
\%(95 \% \mathrm{CI})\end{array}$} & \multicolumn{2}{|c|}{$\begin{array}{c}\text { GLE/PIB } \\
\%(95 \% \text { CI })\end{array}$} \\
\hline & 7.1 & $(6.0-8.2)$ & 3.2 & $(2.9-3.5)$ & $(8.5-10.7)$ & 3.1 & $(2.3-3.8)$ & 4.2 & $(3.1-5.3)$ & 2.5 & $(0.3-4.7)$ \\
\hline Noncirrhotic & 7.2 & $(5.8-8.6)$ & 3.1 & $(2.8-3.4)$ & $(7.8-10.2)$ & 2.8 & $(2.0-3.6)$ & 4.6 & $(3.3-5.8)$ & 2.7 & $(0.4-5.0)$ \\
\hline Cirrhotic & 7.0 & $(5.3-8.7)$ & 3.6 & $(3-4.2 .0)$ & $13.6 \quad(10.1-17.2)$ & 4.2 & $(2.2-6.2)$ & 2.8 & $(0.9-4.7)$ & 0 & \\
\hline Female & 7.8 & $(6.0-9.6)$ & 3.5 & $(3.1-3.9)$ & $11.6 \quad(9.6-13.5)$ & 3.1 & $(2.0-4.3)$ & 4.2 & $(2.5-5.9)$ & 1.9 & $(0.0-4.6)$ \\
\hline Male & 6.7 & $(5.4-8.0)$ & 3.0 & $(2.7-3.3)$ & $(7.0-9.7)$ & 3.1 & $(2.1-4.1)$ & 4.2 & $(2.8-5.5)$ & 3.2 & $(0.0-6.7)$ \\
\hline
\end{tabular}

$C I=$ confidence interval; $E B R / G Z R=$ elbasvir/grazoprevir; $G L E / P I B=$ glecaprevir/pibrentasvir; $L D V / S O F=$ ledipasvir/sofosbuvir; OPrD =ombitasvir/paritaprevir/ritonavir + dasabuvir; SIM/SOF = simeprevir/sofosbuvir; SOF/VEL = sofosbuvir/velpatasvir.

\section{Results}

We identified 41,058 individuals treated with the DAAs of interest between January 2014 and December 2017. After applying exclusion criteria, we selected 26,098 HCV patients. Most of them were treated with LDV/SOF (67.8\%), followed by 9.9\% with OPrD, $8.5 \%$ with SIM/SOF, $7.8 \%$ with SOF/VEL, $5.2 \%$ with EBR/GZR, and $0.8 \%$ with GLE/PIB. The median age was 58 years (interquartile range $53-62$ ), and $60.5 \%$ were male. At baseline, employment, calendar year, past HCV drug use, comorbidity, and previous health care use showed some heterogeneity across groups. Patients starting therapy with SIM/SOF had the highest frequency of cirrhosis (39.9\%); decompensated cirrhosis (18.7\%); and previous use of interferon, ribavirin, boceprevir, or telaprevir (4.7\%). Patients starting therapy with EBR/GZR, SOF/VEL, and GLE/PIB had the lowest frequency of previous $\mathrm{HCV}$ therapy $(<1 \%)$. The use of ribavirin during follow-up was greater in patients using $\operatorname{OPrD}(73.4 \%)$ than in the other groups (range, $0 \%-16 \%$ ). Also, the number of patients starting therapy with SIM/SOF in 2014 was considerably higher compared with 2015/2017 when newer drug regimens were launched in the U.S. market: OPrD in December 2014, and SOF/VEL and EBR/GZR in 2016, and GLE/PIB in 2017 (Table 1).

As shown in Appendix B (available in online article), the distribution of therapies followed similar patterns across health care plans, with GLE/PIB having the lowest use (2\% or less) and LDV/SOF having by far the highest use (60\%-72\%). Medicaid patients had a higher frequency of comorbidities (including cirrhosis, decompensated cirrhosis, and HIV infection) and drug and alcohol abuse compared with patients covered by commercial plans.

Overall, early discontinuation rates (95\% CI) were $7.1 \%$ (6.0-8.2) for SIM/SOF, 3.2\% (2.9-3.5) for LDV/SOF, 9.6\% (8.510.7) for $\mathrm{OPrD}, 3.1 \%$ (2.3-3.8) for SOF/VEL, 4.2\% (3.1-5.3) for EBR/GZR, and 2.5\% (0.3-4.7) for GLE/PIB (Table 2). The unadjusted early discontinuation rates differed across patient strata for $\mathrm{OPrD}$ patients; cirrhotic patients had a higher rate compared with noncirrhotic individuals (13.6\%, 95\% CI = 10.117.2 vs. $9.0 \%, 95 \% \mathrm{CI}=7.8-10.2$; Table 2).
Among patients starting therapy with SIM/SOF, 79.5\% (95\% $\mathrm{CI}=77.8-81.2)$ received 12 weeks. Most of LDV/SOF users received either 8 weeks $(24.0 \%, 95 \% \mathrm{CI}=23.4-24.6)$ or 12 weeks $(61.4 \%, 95 \% \mathrm{CI}=60.7-62.2)$, although among patients with cirrhosis, $24.4 \%$ (95\% CI=22.9-25.8) received 24 weeks. Among OPrD users, $73.0 \%(95 \% \mathrm{CI}=71.3-74.8)$ received 12 weeks, and 8.6\% (95\% CI=7.5-9.7) received 24 weeks. Considering only initiators of OPrD with cirrhosis, 24.3\% (95\% $\mathrm{CI}=19.7-28.9$ ) received 24 weeks. Among SOF/VEL users, 90.1\% (95\% CI =88.8-91.5) received 12 weeks. Among EBR/ GZR users, 85.4\% (95\% CI =83.5-87.3) received 12 weeks, and $5.5 \%(95 \% \mathrm{CI}=4.2-6.8)$ received 16 weeks. Most of GLE/PIB users received either 8 weeks $(74.9 \%, 95 \% \mathrm{CI}=68.8-80.9)$ or 12 weeks ( $16.1 \%, 95 \% \mathrm{CI}=9.7-22.6)$, although among patients with cirrhosis, therapy with 12 weeks was more common (75.0\%, 95\% CI =45.0-100; Table 3).

Early discontinuation rates differed across patients who initiated therapy with different regimens, as indicated by the significant 5-degree-of-freedom likelihood ratio test $(P<0.0001)$. In multivariable analyses, compared with $\mathrm{OPrD}$ initiators, patients starting SIM/SOF, LDV/SOF, SOF/VEL, EBR/GZR, or GLE/PIB had a significantly smaller chance of discontinuing therapy before 8 weeks. Women, patients with baseline anemia, and those covered by Medicare and Medicaid were more likely to discontinue therapy before 8 weeks than other groups, whereas older age was associated with lower early discontinuation rates. We were unable to establish any statistically significant effects related to other baseline comorbidities (including cirrhosis and HIV infection), drug or alcohol use, ribavirin during follow-up, or past health care use (Table 4).

Among Medicaid patients, the 5-degree-of-freedom likelihood ratio test for differences in the frequency of early discontinuation by different drug regimens was significant $(P<0.0001)$. In multivariable analyses, therapy with LDV/SOF, SOF/VEL, EBR/GZR, or GLE/PIB tended to lower early discontinuation rate compared with those patients using OPrD. We were not able to demonstrate a statistically significant difference between SIM/SOF and OPrD initiators. Anemia did not remain significantly associated with the probability of early discontinuation, and the association with race was not 
Direct-Acting Antivirals for Hepatitis C: Predictors of Early Discontinuation in the Real World

TABLE 3 Proportion (95\% Cl) of Patients Receiving 8, 12, 16, and 24 Weeks of Therapy

Duration of Therapy
$\begin{aligned} & \text { D } \\ & \text { \% }(95 \% \text { CI })\end{aligned}$

statistically significant either. History of alcohol abuse was statistically associated with greater chance of early discontinuation (Table 5).

\section{Discussion}

In this population-based cohort study of $\mathrm{HCV}$ patients, we investigated therapy duration and early discontinuation in 6 interferon-free regimens with second-generation DAAs for 2014-2017 in the United States. To the best of our knowledge, this study is the first of its kind for SOF/VEL, EBR/GZR, and GLE/PIB regimens. LDV/SOF, the first fixed-dose combination approved for HCV in the United States, was the most frequently used regimen. Use of SIM/SOF has greatly decreased as of 2015, whereas prescriptions of other fixed-dose combinations (OPrD, EBR/GZR, SOF/VEL, and GLE/PIB) have increased.

The choice of the drug regimen and duration of the HCV therapy is based on the presence of cirrhosis and other comorbidities, previous treatment failures, and virus genotype. ${ }^{3}$ Our study showed that therapy duration varied across DAA regimens and followed guideline recommendations. Most HCV patients received therapy for 8-12 weeks; fewer patients went through 16-week and 24-week therapy courses. We observed that patients with cirrhosis had longer duration of therapy in some drug regimens. For example, among users of LDV/SOF with cirrhosis, 12 or 24 weeks of therapy were more common; a similar trend was observed in users of GLE/PIB with cirrhosis who more frequently received 12 weeks versus 8 weeks of therapy. Potentially, the current DAA regimens make therapy suitable for all patients. SOF/VEL and GLE/PIB are pangenotypic regimens; OPrD, EBR/GZR, and GLE/PIB are recommended for patients with advanced renal dysfunction; GLE/PIB and SOF/VEL are options for prior treatment failures; and a short course of LDV/SOF is effective in nonblack and HIV-uninfected patients whose HCV RNA levels are $<6$ million IU/mL. ${ }^{26-28}$ The addition of ribavirin or the extension of therapy (often to 24 weeks) can enhance higher effectiveness and may be necessary for some patients. ${ }^{3,26}$

Early discontinuation of treatment before 8 weeks occurred in less than $10 \%$ of patients across the 6 drug regimens. The adjusted analysis demonstrated that patients using SIM/SOF, LDV/SOF, SOF/VEL, EBR/GZR, and GLE/PIB were less likely than those using $O P r D$ to discontinue early. Three quarters of OPrD initiators used ribavirin concomitantly. The high pill burden and adverse events associated with ribavirin-containing regimens may explain the higher rate of early discontinuation. ${ }^{29}$ Studies following patients covered by commercial plans and Medicare in the United States in 2013-2015 showed that $12 \%$ using SOF-based regimens (SOF plus ribavirin, SIM/SOF, LDV/SOF) or OPrD discontinued therapy. ${ }^{30}$ The majority of patients (92\% and $89 \%$, respectively) completed 12 weeks of treatment with SIM/SOF and SIM/SOF plus ribavirin ${ }^{31} ; 81 \%$ and $91 \%$ had high adherence to SIM/SOF with or without ribavirin and to LDV/SOF, respectively. ${ }^{15} \mathrm{~A}$ study in a cohort of American veterans with HCV genotype 1 found that $85 \%$ of patients using OPrD with or without ribavirin completed at least 12 weeks of therapy, and 95\% of patients using LDV/ SOF with or without ribavirin completed at least 8 weeks of therapy. ${ }^{13}$ Another study of American veterans reported early discontinuation ( $<8$ weeks) in $9 \%$ of patients using OPrD with or without ribavirin and less than $6 \%$ for LDV/SOF with 


\begin{tabular}{|c|c|c|}
\hline $\begin{array}{cl}\text { TABLE } 4 \text { Adjusted } \\
\\
\text { Discontin }\end{array}$ & $\begin{array}{l}\text { and } 95 \% \mathrm{C} \\
\text { on } 1 \mathrm{~N}=26,0\end{array}$ & r Early \\
\hline Covariates & Adjusted OR & $95 \% \mathrm{CI}$ \\
\hline \multicolumn{3}{|l|}{ Drug regimen } \\
\hline OPrD & Reference & - \\
\hline SIM/SOF & 0.53 & $0.37-0.74$ \\
\hline LDV/SOF & 0.31 & $0.25-0.38$ \\
\hline SOF/VEL & 0.26 & $0.19-0.37$ \\
\hline EBR/GZR & 0.33 & $0.23-0.47$ \\
\hline GLE/PIB & 0.18 & $0.07-0.46$ \\
\hline Use of ribavirin during follow-up & 1.12 & $0.91-1.37$ \\
\hline Age (5-year increments) & 0.92 & $0.89-0.95$ \\
\hline Sex (female vs. male) & 1.17 & $1.03-1.33$ \\
\hline \multicolumn{3}{|l|}{ Year of cohort entry } \\
\hline 2014 & Reference & - \\
\hline 2015 & 0.74 & $0.57-0.95$ \\
\hline 2016 & 0.62 & $0.48-0.82$ \\
\hline 2017 & 0.71 & $0.53-0.95$ \\
\hline \multicolumn{3}{|l|}{ Health plan coverage } \\
\hline Commercial plans & Reference & - \\
\hline Medicare & 1.63 & $1.30-2.05$ \\
\hline Medicaid & 1.55 & $1.34-1.78$ \\
\hline Cirrhosis & 1.03 & $0.87-1.22$ \\
\hline Anemia & 1.27 & $1.03-1.56$ \\
\hline Diabetes & 1.17 & $0.99-1.38$ \\
\hline HIV infection & 1.14 & $0.76-1.72$ \\
\hline Charlson Comorbidity Index & 1.01 & $0.97-1.05$ \\
\hline Drug abuse & 1.16 & $0.93-1.45$ \\
\hline Alcohol abuse & 1.12 & $0.89-1.41$ \\
\hline Number of physician visits & 1.00 & $1.00-1.01$ \\
\hline Number of ED visits & 1.02 & $1.00-1.04$ \\
\hline Number of hospitalizations & 1.04 & $0.97-1.11$ \\
\hline \multicolumn{3}{|c|}{$\begin{array}{l}C I=\text { confidence interval; } E B R / G Z R=\text { elbasvir/grazoprevir; } E D=\text { emergency } \\
\text { department; } G L E / P I B=\text { glecaprevir/pibrentasvir; HIV=human immunodeficiency } \\
\text { virus; } L D V / S O F=\text { ledipasvir/sofosbuvir; } O P r D=\text { ombitasvir/paritaprevir/ } \\
\text { ritonavir+dasabuvir; OR=odds ratio; } S I M / S O F=\text { simeprevir/sofosbuvir; } \\
\text { SOF/VEL= sofosbuvir/velpatasvir. }\end{array}$} \\
\hline
\end{tabular}

or without ribavirin. ${ }^{22}$ The German Hepatitis C-Registry also reported low rates of treatment discontinuation for interferonfree regimens, ranging from $0.4 \%$ to $3.2 \% .^{32}$

Our study did not assess reasons for discontinuation of therapy with DAA agents, but previous observational studies have shown that adverse events and inadequate virologic response are some causes of therapy discontinuation. ${ }^{32-34}$ In case of noncompletion and/or therapy failure (patient did not achieve SVR), retreatment should be considered. ${ }^{3}$ Regarding factors associated with second-generation DAAs, our findings suggested that women, patients with anemia at baseline, Medicare and Medicaid patients, and patients with a history of alcohol abuse (subgroup of Medicaid patients) had higher early discontinuation. We were unable to demonstrate significant associations for early discontinuation rates with baseline cirrhosis, HIV infection, drug use, or race (among Medicaid patients). Patients covered by Medicaid had greater drug and alcohol abuse compared with patients covered by Medicare and commercial plans, and both Medicaid and Medicare patients had more comorbidities than patients covered by commercial plans. The combination of these factors may explain higher rates of early discontinuation in Medicaid and Medicare patients. Another study showed that Medicare patients had lower adherence to SIM/SOF regimen. ${ }^{15}$ However, alcohol abuse remains controversial regarding its role in adherence and response to therapy. In a study of marginalized people using drugs and/or alcohol who were receiving DAAs (LDV/SOF, OPrD, EBR/GZR, SOF/daclatasvir), moderate to heavy alcohol use was the only factor statistically associated with lower therapy adherence. ${ }^{35}$ On the other side, 1 study of patients using SOF, LDV/SOF, and OPrD did not clearly show alcohol use to affect sustained virologic remission. ${ }^{22}$

There is increasing evidence suggesting that sex differences may play a role in completion of HCV therapy. One observational cohort study suggested that women were more likely than other groups to discontinue therapy with telaprevir, peginterferon, and ribavirin due to adverse events. ${ }^{12} \mathrm{~A}$ meta-analysis of clinical trials in HIV/HCV coinfected patients reported that women were more likely than other groups to experience adverse events requiring HCV treatment discontinuation or dose modification. ${ }^{26}$ Age and sex interactions may exist, as women younger than aged 40 years have been shown to have greater response to peginterferon with or without ribavirin,,$^{37,38}$ while postmenopausal women were less likely to have a sustained virologic response to interferon and ribavirin. ${ }^{39}$ Another study reported that women were less likely than other subjects to adhere to treatment with SOF plus ribavirin. ${ }^{15}$ We observed that women had a higher chance of early discontinuation than other groups; however, the small magnitude of the effect suggests a need to confirm this association with current DAA therapies in further investigations.

\section{Limitations}

The study has some potential limitations. First, there was a lack of laboratory information, such as hepatitis $C$ genotype and viral load. Second, patients can enter and leave the register in MarketScan databases as their medical insurance changes, making assessment of early drug exposures challenging. Third, data on cirrhosis may have been missing. Those factors drive the choice of drug regimen and therapy duration. Therefore, we could not infer the intended treatment duration. Fourth, the frequency of alcohol or drug abuse may be underestimated by using definitions based on ICD codes in administrative databases.$^{40}$ Fifth, the existence of a filled pharmacy claim does not indicate that the medication was taken as prescribed. In addition, the number of patients starting therapy with GLE/PIB was notably small because the drug regimen was only approved in the United States in August 2017. Finally, although we 


\begin{tabular}{|c|c|c|}
\hline \multicolumn{3}{|c|}{$\begin{array}{l}\text { Adjusted ORs and } 95 \% \text { Cls for Early } \\
\text { Discontinuation in Medicaid-Covered } \\
\text { Patients ( } n=7,931)\end{array}$} \\
\hline Covariates & Adjusted OR & $95 \% \mathrm{CI}$ \\
\hline \multicolumn{3}{|l|}{ Drug regimen } \\
\hline OPrD & Reference & - \\
\hline SIM/SOF & 0.80 & $0.38-1.71$ \\
\hline LDV/SOF & 0.26 & $0.18-0.39$ \\
\hline SOF/VEL & 0.22 & $0.13-0.38$ \\
\hline EBR/GZR & 0.24 & $0.15-0.40$ \\
\hline GLE/PIB & 0.07 & $0.02-0.28$ \\
\hline Use of ribavirin during follow-up & 0.93 & $0.66-1.33$ \\
\hline Age (5-year increments) & 0.91 & $0.86-0.96$ \\
\hline Sex (female vs. male) & 1.15 & $0.94-1.42$ \\
\hline \multicolumn{3}{|l|}{ Year of cohort entry } \\
\hline 2014 & Reference & - \\
\hline 2015 & 1.34 & $0.70-2.59$ \\
\hline 2016 & 1.01 & $0.52-1.97$ \\
\hline 2017 & 1.42 & $0.72-2.82$ \\
\hline Race (black vs. nonblack) & 1.04 & $0.83-1.30$ \\
\hline Cirrhosis & 1.13 & $0.87-1.46$ \\
\hline Anemia & 1.07 & $0.76-1.49$ \\
\hline Diabetes & 1.26 & $0.97-1.64$ \\
\hline HIV infection & 1.33 & $0.73-2.43$ \\
\hline Charlson Comorbidity Index & 0.98 & $0.92-1.04$ \\
\hline Drug abuse & 1.02 & $0.76-1.37$ \\
\hline Alcohol abuse & 1.36 & $1.02-1.82$ \\
\hline Number of physician visits & 1.00 & $0.99-1.01$ \\
\hline Number of ED visits & 1.01 & $0.99-1.04$ \\
\hline Number of hospitalizations & 1.01 & $0.91-1.12$ \\
\hline \multicolumn{3}{|c|}{$\begin{array}{l}\text { CI=confidence interval; EBR/GZR = elbasvir/grazoprevir; } E D=\text { emergency } \\
\text { department; } G L E / P I B=\text { glecaprevir/pibrentasvir; HIV=human immunodeficiency } \\
\text { virus; } L D V / S O F=\text { ledipasvir/sofosbuvir; OPrD =ombitasvir/paritaprevir/ritonavir } \\
\text { dasabuvir; OR=odds ratio; SIM/SOF = simeprevir/sofosbuvir; } \\
\text { SOF/VEL = sofosbuvir/velpatasvir. }\end{array}$} \\
\hline
\end{tabular}

controlled for demographic and clinical factors, there may have been residual confounding by indication in patients exposed to these agents.

Despite these limitations, our study has many strengths. We used the MarketScan databases, which offer health care data for Americans and their spouses and dependents covered by commercial health insurance, Medicare, and Medicaid. MarketScan databases also contain comprehensive information on outpatient prescriptions, which makes the database a robust tool for research on medication use. This allowed us to create a large sample of HCV patients, including users of recently approved regimens, such as EBR/GZR, SOF/VEL, and GLE/PIB. Thus, ours is the first real-world study on therapy discontinuation of those newer regimens. In addition, our study followed patients initiating DAA therapy from 2014 to 2017, capturing the transition period from use of SIM/SOF to the fixed-dose combinations (LDV/SOF, OPrD, EBR/GZR, SOF/ VEL, and GLE/PIB).

\section{Conclusions}

These real-world data demonstrate that although patients using OPrD appeared more likely to discontinue therapy before 8 weeks than those using other second-generation DAAs, the overall rate of early discontinuation was lower than $10 \%$, and most patients received DAA therapy for 8 or 12 weeks. Early discontinuation was more common in women, patients with baseline anemia, and Medicare and Medicaid patients. Future research focusing on these factors, particularly sex and gender issues, may help further optimize care of patients with HCV.

\section{Authors}

MARINA AMARAL DE ÁVILA MACHADO, PhD; CRISTIANO SOARES DE MOURA, PhD; MARIE-EVE BEAUCHAMP, PhD; MARINA B. KLEIN, MD, MSc; and SASHA BERNATSKY, MD, $P h D$, Research Institute of the McGill University Health Centre, Montreal, Quebec, Canada. MICHAL ABRAHAMOWICZ, PhD, Department of Epidemiology, Biostatistics and Occupational Health, McGill University, Montreal, Quebec, Canada. KEVIN WINTHROP, MD, MPH, Oregon Health \& Science University, Portland; BRUCE CARLETON, BSc, PharmD, University of British Columbia, Vancouver, British Columbia, Canada; JORDAN J. FELD, MD, MPH, Toronto Centre for Liver Disease, University of Toronto University Health Network, Toronto, Ontario, Canada; and JEFFREY R. CURTIS, MD, MS, MPH, University of Alabama at Birmingham.

AUTHOR CORRESPONDENCE: Sasha Bernatsky, MD, PhD, Research Institute of the McGill University Health Centre, $5252 \mathrm{Blvd}$. de Maisonneuve O, \#3F.51, Montréal, Quebec, Canada H4A 355. Tel.: 514.934.1934 ext. 44710; E-mail: sasha.bernatsky@mcgill.ca.

\section{DISCLOSURES}

This study was funded by the Canadian Institutes of Health Research Klein has received grants for investigator-initiated trials from ViiV Healthcare, Janssen, Gilead, and Merck, as well as consulting fees from ViiV Healthcare, Merck, and AbbVie. Feld has received research support and/or scientific consulting fees from AbbVie, Contravir, Enanta, Gilead, Janssen, Merck, and Wako. All other authors have no conflicts of interest to declare.

Results from this study were presented as a poster at the 34th International Conference of Phamacoepidemiology and Therapeutic Risk Management; August 22-26, 2018; Prague, Czech Republic.

\section{REFERENCES}

1. Centers for Disease Control and Prevention. Hepatitis C information. Available at: https://www.cdc.gov/hepatitis/hcv/. Accessed April 5, 2019

2. World Health Organization. Global Hepatitis Report 2017. Geneva: World Health Organization; 2017. Available at: https://apps.who.int/iris/bitstream/ handle/10665/255016/9789241565455-eng.pdf;jsessionid=23721C7D244C9 4A28E7791F325BFEB3F?sequence=1. Accessed April 24, 2019.

3. American Association for the Study of Liver Diseases and the Infectious Diseases Society of America. HCV guidance: recommendations for testing, managing, and treating hepatitis C. September 21, 2017. Available at: https:// www.hcvguidelines.org/. Accessed April 5, 2019. 
4. Ferreira VL, Leonart LP, Tonin FS, Borba HHL, Pontarolo R. Sustained virological response in special populations with chronic hepatitis $C$ using interferon-free treatments: a systematic review and meta-analysis of observational cohort studies. Clin Drug Investig. 2018;38(5):389-400.

5. Berden FA, Aaldering BR, Groenewoud H, IntHout J, Kievit W, Drenth JP. Identification of the best direct-acting antiviral regimen for patients with hepatitis $C$ virus genotype 3 infection: a systematic review and network meta-analysis. Clin Gastroenterol Hepatol. 2017;15(3):349-59.

6. Ahmed H, Abushouk AI, Attia A, et al. Safety and efficacy of sofosbuvir plus velpatasvir with or without ribavirin for chronic hepatitis $C$ virus infection: a systematic review and meta-analysis. J Infect Public Health. 2018;11(2):156-64.

7. Flamm SL, Bacon B, Curry MP, et al. Real-world use of elbasvir-grazoprevir in patients with chronic hepatitis C: retrospective analyses from the TRIO network. Aliment Pharmacol Ther. 2018;47(11):1511-22.

8. Butt AA, McGinnis KA, Skanderson M, Justice AC. Hepatitis C treatment completion rates in routine clinical care. Liver Int. 2010;30(2):240-50.

9. Lo Re V 3rd, Teal V, Localio AR, Amorosa VK, Kaplan DE, Gross R. Relationship between adherence to hepatitis $C$ virus therapy and virologic outcomes: a cohort study. Ann Intern Med. 2011;155(6):353-60.

10. McHutchison JG, Manns M, Patel K, et al. Adherence to combination therapy enhances sustained response in genotype-l-infected patients with chronic hepatitis C. Gastroenterology. 2002;123(4):1061-69.

11. Majid A, McAninch J, Morgan DJ, et al. Predictors of early treatment discontinuation in a cohort of patients treated with boceprevir-based therapy for hepatitis C infection. J Viral Hepat. 2014;21(8):585-89.

12. Ide K, Kawasaki Y, Iketani R, Masaki N. Risk factors for treatment discontinuation caused by adverse events when using telaprevir, peginterferon and ribavirin to treat chronic hepatitis $\mathrm{C}$ : a real-world retrospective cohort study. Biol Pharm Bull. 2017;40(5):645-49.

13. Backus LI, Belperio PS, Shahoumian TA, Loomis TP, Mole LA. Comparative effectiveness of ledipasvir/sofosbuvir \pm ribavirin vs. ombitasvir/paritaprevir/ ritonavir + dasabuvir \pm ribavirin in 6961 genotype 1 patients treated in routine medical practice. Aliment Pharmacol Ther. 2016;44(4):400-10.

14. Reddy KR, Lim JK, Kuo A, et al. All-oral direct-acting antiviral therapy in HCV-advanced liver disease is effective in real-world practice: observations through HCV-TARGET database. Aliment Pharmacol Ther. 2017:45(1):115-26.

15. Yin S, Barker L, White JZ, Jiles RB. Sofosbuvir-based regimens for chronic hepatitis $C$ in a well-insured U.S. population: patient characteristics, treatment adherence, effectiveness, and health care costs, 2013-2015. J Manag Care Spec Pharm. 2019;25(2):195-210. Available at: https://www. jmcp.org/doi/10.18553/jmcp.2019.25.2.195.

16. Sarpel D, Wasserman I, Trochtenberg A, et al. Non-adherence is the most important risk factor for ledipasvir/sofosbuvir HCV treatment failure in the real world. Poster presented at: 2016 AASLD Liver Meeting. November 11-15, 2016. Boston, MA. Abstract 1978. Available at: http://www.natap. org/2016/AASLD/AASLD_75.htm. Accessed April 24, 2019.

17. Meyer JP, Moghimi Y, Marcus R, Lim JK, Litwin AH, Altice FL. Evidencebased interventions to enhance assessment, treatment, and adherence in the chronic Hepatitis C care continuum. Int J Drug Policy. 2015;26(10):922-35.

18. Morrill JA, Shrestha M, Grant RW. Barriers to the treatment of hepatitis C: patient, provider, and system factors. J Gen Intern Med. 2005;20(8):754-58.

19. Hansen L. The Truven Health MarketScan Databases for life sciences researchers. March 2017. Available at: http://truvenhealth.com/Portals/0/ Assets/2017-MarketScan-Databases-Life-Sciences-Researchers-WP.pdf. Accessed April 5, 2019.

20. Social Security Administration. Medicare benefits. Available at: https:// www.ssa.gov/benefits/medicare/. Accessed April 5, 2019.

21. Centers for Medicare \& Medicaid Services. Medicaid eligibility. Available at: https://www.medicaid.gov/medicaid/eligibility/index.html. Accessed April 5, 2019.
22. Ioannou GN, Beste LA, Chang MF, et al. Effectiveness of sofosbuvir, ledipasvir/sofosbuvir, or paritaprevir/ritonavir/ombitasvir and dasabuvir regimens for treatment of patients with hepatitis $C$ in the Veterans Affairs National Health Care System. Gastroenterology. 2016;151(3):457-471.e5.

23. Quan H, Sundararajan V, Halfon P, et al. Coding algorithms for defining comorbidities in ICD-9-CM and ICD-10 administrative data. Med Care. 2005;43(11):1130-39.

24. Lapointe-Shaw L, Georgie F, Carlone D, et al. Identifying cirrhosis, decompensated cirrhosis and hepatocellular carcinoma in health administrative data: a validation study. PLoS One. 2018;13(8):e0201120.

25. Niu B, Forde KA, Goldberg DS. Coding algorithms for identifying patients with cirrhosis and hepatitis $B$ or $C$ virus using administrative data. Pharmacoepidemiol Drug Saf. 2015;24(1):107-11.

26. Behara R, Reau N. Updates on hepatitis $C$ virus therapy in the directacting antiviral era. Curr Opin Gastroenterol. 2017;33(3):115-19.

27. Vermehren J, Park JS, Jacobson IM, Zeuzem S. Challenges and perspectives of direct antivirals for the treatment of hepatitis $C$ virus infection. J Hepatol. 2018;69(5):1178-87.

28. Carrion AF, Martin P. Glecaprevir + pibrentasvir for treatment of hepatitis C. Expert Opin Pharmacother. 2018;19(4):413-19.

29. Tong MJ, Chang PW, Huynh TT, Rosinski AA, Tong LT. Adverse events associated with ribavirin in sofosbuvir-based therapies for patients with chronic hepatitis C: a community practice experience. J Dig Dis. 2016;17(2):113-21.

30. Puenpatom A, Hull M, McPheeters J, Schwebke K. Disease burden, early discontinuation, and healthcare costs in hepatitis $C$ patients with and without chronic kidney disease treated with interferon-free direct-acting antiviral regimens. Clin Drug Investig. 2017;37(7):687-97.

31. Walker DR, Juday TR, Manthena SR, Jing Y, Sood V. The impact of ribavirin on real-world adherence rates in hepatitis $C$ patients treated with sofosbuvir plus simeprevir. Clinicoecon Outcomes Res. 2015;7:637-42.

32. Höner Zu Siederdissen C, Buggisch P, Böker K, et al. Treatment of hepatitis $C$ genotype 1 infection in Germany: effectiveness and safety of antiviral treatment in a real-world setting. United European Gastroenterol J. 2018;6(2):213-24

33. Miotto N, Mendes LC, Zanaga LP, et al. Predictors of early discontinuation of interferon-free direct antiviral agents in patients with hepatitis $C$ virus and advanced liver fibrosis: results of a real-life cohort. Eur J Gastroenterol Hepatol. 2017;29(10):1149-54.

34. Trombatt WD, Koerner PH, Craft ZN, Miller RT, Kamal KM. Retrospective analysis of the medication utilization and clinical outcomes of patients treated with various regimens for hepatitis C infection. J Pharm Pract. 2017;30(2):154-61.

35. Mason K, Dodd Z, Guyton M, et al. Understanding real-world adherence in the directly acting antiviral era: a prospective evaluation of adherence among people with a history of drug use at a community-based program in Toronto, Canada. Int J Drug Policy. 2017;47:202-08.

36. Bhattacharya D, Umbleja T, Carrat F, et al. Women experience higher rates of adverse events during hepatitis $C$ virus therapy in HIV infection: a meta-analysis. J Acquir Immune Defic Syndr. 2010;55(2):170-75.

37. Hayashi J, Kishihara Y, Ueno K, et al. Age-related response to interferon alfa treatment in women vs men with chronic hepatitis $C$ virus infection. Arch Intern Med. 1998;158(2):177-81.

38. Yu JW, Sun LJ, Zhao YH, Kang P, Yan BZ. Impact of sex on virologic response rates in genotype 1 chronic hepatitis $C$ patients with peginterferon alpha-2a and ribavirin treatment. Int J Infect Dis. 2011;15(11):e740-46.

39. Villa E, Karampatou A, Cammà C, et al. Early menopause is associated with lack of response to antiviral therapy in women with chronic hepatitis C. Gastroenterology. 2011;140(3):818-29.

40. Boscarino JA, Moorman AC, Rupp LB, et al. Comparison of ICD-9 codes for depression and alcohol misuse to survey instruments suggests these codes should be used with caution. Dig Dis Sci. 2017;62(10):2704-12. 


\begin{tabular}{|c|c|c|}
\hline \multicolumn{3}{|c|}{ APPENDIX A List of Codes Used in Study } \\
\hline Condition & ICD-9-CM & ICD-10-CM \\
\hline HCV infection & $\begin{array}{l}\text { 070.51, 070.54, 070.70, } \\
\text { V02.62 }\end{array}$ & $\begin{array}{l}\text { B17.10, B18.2, B19.20, } \\
\text { Z22.52 }\end{array}$ \\
\hline Cirrhosis & $4561,5712,5715$ & $\begin{array}{l}\text { K7030, I859, I982, } \\
\text { K703,K717,K746 }\end{array}$ \\
\hline $\begin{array}{l}\text { Decompensated } \\
\text { cirrhosis }\end{array}$ & $\begin{array}{l}4560,4562,5722,5723 \\
5724,7824,7895\end{array}$ & $\begin{array}{l}\text { I850, I864, I983, K721, } \\
\text { K729, K766, K767, I9820, } \\
\text { R17, R18, }\end{array}$ \\
\hline Anemia & $\begin{array}{l}280,2819,2859,2848, \\
2852\end{array}$ & $\begin{array}{l}\text { D50, D649, D539, D60, } \\
\text { D611, D612, D6189, D63 }\end{array}$ \\
\hline Diabetes & $\begin{array}{l}2500,2501,2502, \\
2503,2507,2504,2505 \\
2506\end{array}$ & $\begin{array}{l}\text { E100, E101, E106, E108, } \\
\text { E109,E110, E111, E116, } \\
\text { E118, E119, E120, E121, } \\
\text { E126, E128, E129, E130, } \\
\text { E131, E136, E138,E139, } \\
\text { E140, E141, E146, E148, } \\
\text { E149, E102, E103, E104, } \\
\text { E105, E107, E112, E113, } \\
\text { E114, E115, E117, E122, } \\
\text { E123, E124, E124, E127, } \\
\text { E132, E133, E134, E135, } \\
\text { E137, E142, E143, E144, } \\
\text { E145, E147 }\end{array}$ \\
\hline HIV infection & $042,043,044$ & B20, B21, B22, B24 \\
\hline Alcohol abuse & $\begin{array}{l}2911,2912,2915,2916 \\
2917,2918,2919,3039 \\
3050\end{array}$ & $\begin{array}{l}\text { F10, E52, T51, V113, } \\
\text { G621, I426, K292, K700, } \\
\text { K703, K709, Z502, Z714, } \\
\text { Z721 }\end{array}$ \\
\hline Drug abuse & $\begin{array}{l}2920,29282,29283, \\
29284,29285,29286, \\
29287,29288,29289, \\
2929,3040,3052,3053, \\
3054,3055,3056,3057, \\
3058,3059\end{array}$ & $\begin{array}{l}\text { F11, F12, F13, F14, F15, } \\
\text { F16, F18, F19, Z715, Z722 }\end{array}$ \\
\hline
\end{tabular}

HCV=hepatitis $C$ virus; HIV=human immunodeficiency virus;

ICD-9-CM = International Classification of Diseases, Ninth Revision, Clinical Modification; ICD-10-CM = International Classification of Diseases, Tenth

Revision, Clinical Modification. 


\section{APPENDIX B Baseline Characteristics According to Health Plan Coverage $(N=26,098)$}

Variables

Commercial Plans

$15,599(59.8 \%)$

Medicare

$2,568(9.8 \%)$

Drug regimen, $\mathrm{n}(\%)$

\begin{tabular}{l} 
SIM/SOF \\
LDV/SOF \\
\hline OPrD \\
\hline SOF/VEL \\
\hline EBR/GZR \\
\hline GLE/PIB
\end{tabular}

Male, $\mathrm{n}(\%)$

Age, years, median (IQR)

Year of cohort entry, n (\%)

\begin{tabular}{|c|c|c|c|c|c|c|}
\hline 2014 & 2,867 & $(18.4)$ & 530 & $(20.6)$ & 635 & $(8.0)$ \\
\hline 2015 & 6,117 & $(39.2)$ & 1,008 & (39.3) & 2,079 & $(26.2)$ \\
\hline 2016 & 3,808 & $(24.4)$ & 675 & $(26.3)$ & 2,471 & $(31.2)$ \\
\hline 2017 & 2,807 & $(18.0)$ & 355 & $(13.8)$ & 2,746 & $(34.6)$ \\
\hline Urban, $\mathrm{n}(\%)^{\mathrm{a}}$ & 14,062 & $(90.2)$ & 2,398 & $(93.4)$ & - & \\
\hline Full-time employment, n (\%)a & 9,605 & $(61.6)$ & 391 & $(15.2)$ & - & \\
\hline \multicolumn{7}{|l|}{ Race, $\mathrm{n}(\%)^{\mathrm{b}}$} \\
\hline White & \multicolumn{2}{|c|}{-} & \multicolumn{2}{|c|}{-} & 3,724 & $(49.6)$ \\
\hline Black & \multicolumn{2}{|c|}{-} & \multicolumn{2}{|c|}{-} & 2,580 & (34.3) \\
\hline Hispanic & \multicolumn{2}{|c|}{-} & \multicolumn{2}{|c|}{-} & 119 & (1.6) \\
\hline Other & \multicolumn{2}{|c|}{-} & \multicolumn{2}{|c|}{-} & 1,090 & $(14.5)$ \\
\hline Charlson Comorbidity Index, mean (SD) & 1.6 & $(2.0)$ & 2.5 & $(2.5)$ & 2.5 & $(2.5)$ \\
\hline \multicolumn{7}{|l|}{ Comorbities, n (\%) } \\
\hline Cirrhosis & 2,686 & $(17.2)$ & 606 & $(23.6)$ & 2,218 & $(28.0)$ \\
\hline Anemia & 1,132 & $(7.3)$ & 356 & $(13.9)$ & 894 & $(11.3)$ \\
\hline Decompensated cirrhosis & 1,173 & $(7.5)$ & 234 & $(9.1)$ & 1,053 & $(13.3)$ \\
\hline Diabetes & 2,750 & $(17.6)$ & 778 & $(30.3)$ & 1,781 & (22.5) \\
\hline HIV infection & 408 & $(2.6)$ & 35 & $(1.4)$ & 363 & $(4.6)$ \\
\hline Drug abuse & 871 & $(5.6)$ & 77 & (3.0) & 1,146 & $(14.5)$ \\
\hline Alcohol abuse & 838 & $(5.4)$ & 96 & $(3.7)$ & 1,129 & $(14.2)$ \\
\hline Past use of interferon, ribavirin, telaprevir, or boceprevir, $\mathrm{n}(\%) \mathrm{c}$ & 1,089 & $(7.0)$ & 178 & $(6.9)$ & 400 & $(5.0)$ \\
\hline Interferon & 875 & $(5.6)$ & 166 & $(6.5)$ & 299 & $(3.8)$ \\
\hline Ribavirin & 1,076 & $(6.9)$ & 172 & $(6.7)$ & 394 & $(5.0)$ \\
\hline Telaprevir & 565 & (3.6) & 94 & $(3.7)$ & 124 & (1.6) \\
\hline Boceprevir & 213 & $(1.4)$ & 45 & $(1.8)$ & 91 & $(1.2)$ \\
\hline Number of physician visits, mean (SD) & 11.6 & $(11.2)$ & 15.8 & $(14.6)$ & 14.7 & $(16.4)$ \\
\hline Number of ED visits, mean (SD) & 0.5 & $(1.2)$ & 0.5 & $(1.2)$ & 2 & $(3.6)$ \\
\hline Number of hospitalizations, mean (SD) & 0.2 & $(0.7)$ & 0.2 & $(0.6)$ & 0.5 & $(1.1)$ \\
\hline
\end{tabular}

a Missing values for Medicaid-covered patients $(n=7,931)$

${ }^{b}$ Missing values for commercial plans and Medicare-covered patients $(n=18,585)$

cUse in the year before cohort entry.

$E B R / G Z R=$ elbasvir/grazoprevir; $E D=$ emergency department; $G L E / P I B=$ glecaprevir/pibrentasvir; HIV=human immunodeficiency virus; IQR=interquartile range; LDV/SOF = ledipasvir/sofosbuvir; $O \operatorname{PrD}=$ ombitasvir/paritaprevir/ritonavir + dasabuvir; $S D=$ standard deviation; SIM/SOF = simeprevir/sofosbuvir;

SOF/VEL = sofosbuvir/velpatasvir.

\begin{tabular}{rr|rr|rr}
1,468 & $(9.4)$ & 314 & $(12.2)$ & 442 & $(5.6)$ \\
\hline 11,095 & $(71.1)$ & 1,859 & $(72.4)$ & 4,734 & $(59.7)$ \\
\hline 1,773 & $(11.4)$ & 140 & $(5.5)$ & 677 & $(8.5)$ \\
\hline 1,026 & $(6.6)$ & 120 & $(4.7)$ & 890 & $(11.2)$ \\
\hline 192 & $(1.2)$ & 125 & $(4.9)$ & 1,044 & $(13.2)$ \\
\hline 45 & $(0.3)$ & 10 & $(0.4)$ & 144 & $(1.8)$ \\
\hline 9,588 & $(61.5)$ & 1,618 & $(63)$ & 4,589 & $(57.9)$ \\
\hline 58 & $(53-61)$ & 67 & $(65-70)$ & 57 & $(51-60)$ \\
\hline \multicolumn{7}{|c|}{50} & & \\
\hline 2,867 & $(18.4)$ & 530 & $(20.6)$ & 635 & $(8.0)$ \\
\hline 6,117 & $(39.2)$ & 1,008 & $(39.3)$ & 2,079 & $(26.2)$ \\
\hline 3,808 & $(24.4)$ & 675 & $(26.3)$ & 2,471 & $(31.2)$ \\
\hline 2,807 & $(18.0)$ & 355 & $(13.8)$ & 2,746 & $(34.6)$ \\
\hline 14,062 & $(90.2)$ & 2,398 & $(93.4)$ & \multicolumn{2}{c}{-} \\
\hline 9,605 & $(61.6)$ & 391 & $(15.2)$ & \multicolumn{2}{c}{-} \\
\hline
\end{tabular}

Medicaid $7,931(30.4 \%)$ 